\title{
A new cryptic ground beetle species from the Alps characterised via geometric morpho- metrics
}

\author{
Angela Roggero ${ }^{1,3}$, Pier Mauro Giachino ${ }^{2}$, Claudia Palestrini ${ }^{1}$ \\ ${ }^{1}$ Department of Life Sciences and Systems Biology, via Accademia Albertina 13, 10123 Torino, Italy \\ ${ }^{2}$ Regione Piemonte, Settore Fitosanitario Regionale, Environment Park, Palazzina A2, via Livorno 60, 10144 \\ Torino, Italy \\ ${ }^{3}$ E-mail:angela.roggero@unito.it
}

Key words: semilandmarks method, Carabidae, Nebria, Nebriola, new species

\begin{abstract}
The European Alps support several ground beetle Nebria ( $\mathrm{Ne}$ briola) species, which are morphologically similar. A study conducted on a Nebriola population located between the Eastern Pennine and Western Lepontine Italian Alps revealed the presence of two species, Nebria (Nebriola) cordicollis and $N$. (Nebriola) gosteliae, and some individuals that possibly represented an unknown taxonomic unit (UTU). Therefore, to further elucidate and characterise the morphological units at the site, we completed a comparative analysis using geometric morphometrics applying the semilandmarks approach. We examined the pronotum, the right elytron, and the median lobe of aedeagus. The quantitative analysis evaluated the overall variation in shape and size of the three structures. Results supported the hypothesised presence of three distinct groups of individuals, with different morphologies for the anatomical traits examined. The pronotum and median lobe of aedeagus exhibited more marked differences among the groups, while the right elytron showed reduced differentiation. These results confirmed that the three groups were separate taxa, and were therefore correctly classified. Based on our findings, we considered the UTU a new species, which is here described as Nebria (Nebriola) casalei $\mathrm{sp}$. nov.
\end{abstract}

\section{Contents}

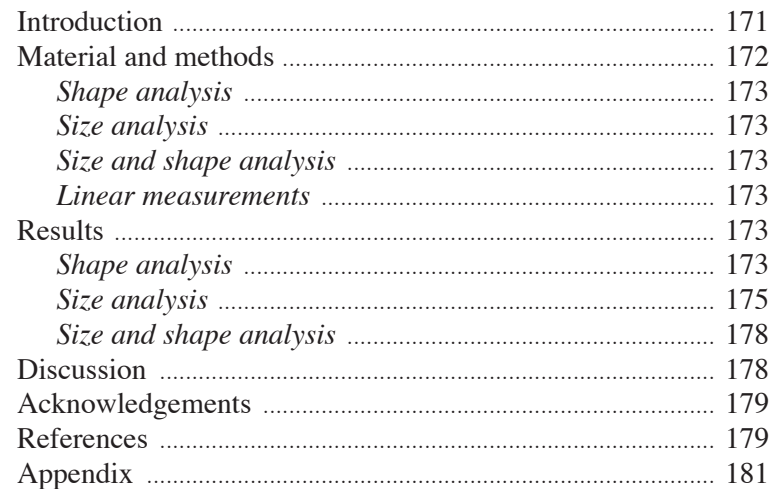

\section{Introduction}

Currently, the most widely accepted ground beetle subgenus Nebriola Daniel, 1903 (Coleoptera, Carabidae, Nebriinae, Nebria) (sensu Lorenz, 2005) nomenclature includes seven species (Daniel, 1903; Löbl and Smetana, 2003; Ledoux and Roux, 2005; Lorenz, 2005; Huber et al., 2010), plus an eighth species (Nebria praegensis Huber and Molenda, 2004, with an equivocal taxonomic status (Huber and Molenda, 2004; Huber et al., 2010).

Nebriola are wingless carabids, resulting in low capacity for dispersion, which confines the species to high-mountain environments equivalent to 'altitudinal islands'. The Nebria species of the subgenus Nebriola are restricted to extreme wet and cold habitat types. Nebria morula Daniel and Daniel, 1891, N. gosteliae Huber, 2010, and N. pictiventris Fauvel, 1888 show a very small, and probably relict geographic distribution, while the other four species of the subgenus ( $N$. cordicollis Chaudoir, 1837, N. fontinalis Daniel and Daniel, 1890, N. lariollei Germiny, 1865, and N. laticollis Dejean, 1826) are more widely distributed in the central western Alps and Pyrenees, but are polytypic and exhibit high intra-specific variability (Ledoux and Roux, 2005).

Nebriola species are characterised by fairly homogeneous external morphology, which to date has resulted in a high level of uncertainty in taxonomic classification (Jeannel, 1941; Bänninger 1949-50; Bari, 1971; Focarile, 1976; Focarile and Casale, 1978; Casale and Vigna Taglianti, 1993; Bisio, 1998; Löbl and Smetana, 2003; Vigna Taglianti, 2005; Lorenz, 2005; Ledoux and Roux, 2005, Huber et al., 2010). Species identification is often difficult; therefore it has been hypothesised that several distinct entities remain unrecognised in 
Nebriola, i.e. cryptic species according to Seifert's (2009) definition.

Recently, Palestrini et al. (2012) examined the evolution of shape and size divergence in $N$. laticollis, $N$. cordicollis, and $N$. fontinalis extending analyses from species to cisalpine subspecies, and populations of $N$. cordicollis. Well-characterised morphologies were identified at the specific level, but the results remained inconclusive at lower taxonomic levels (Palestrini et al., 2012). The three species have relatively widespread distributions, which include regions of environmental extremes, typical of high altitudes. In addition, populations are ecologically reproductively isolated, which has the potential to lead to divergence and subsequent speciation.

The objectives of the present study were to analyse overall shape and size variation of morphological structures within and among the three distinct taxonomic units. Size variation was investigated using traditional morphometrics (TM) approaches, while shape variation was examined employing geometric morphometrics (GM) approaches. The GM method is highly suitable to examine within and among population variation and differentiation, and commonly used in insects to evaluate shape variation, since it is very sensitive and can account also for small-rate variations. In addition, the reliability of taxa delimitation based on the shape of the examined structures is tested through the GM methods.

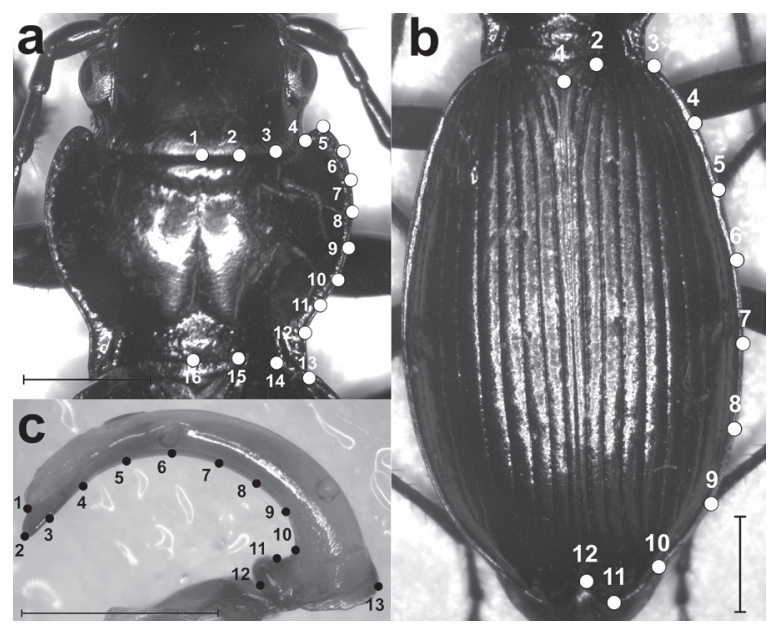

Fig. 1. Landmark and semilandmark configurations of: a) the right half pronotum (16 points), b) the outer edge of the right elytron (12 points) and c) the marginal side of the median lobe of aedeagus (13 points).

\section{Material and methods}

Two known Nebriola species (N.cordicollis and N. gosteliae) were examined with a number of undetermined specimens. All specimens were collected from Northwestern Italy, in the Pennine-Lepontine Alps. We could not definitively assign a number of individuals to any known Nebriola species; therefore these individuals

Table 1. Predicted group membership and cross validated percent values of Canonical variate analysis for studied anatomical traits with sample size (total number $n$ ).

\begin{tabular}{|c|c|c|c|c|c|c|c|c|}
\hline & & \multicolumn{2}{|c|}{$\begin{array}{l}\text { cross-validated } \\
\% \text { correct }\end{array}$} & \multicolumn{3}{|c|}{ predicted group membership } & \multirow{2}{*}{\multicolumn{2}{|c|}{ total number }} \\
\hline & & & & $N . C$ & N. gosteliae & UTU & & \\
\hline \multirow[t]{4}{*}{ pronotum } & N. cordicollis & & 99 & & 97 & 0 & 1 & 98 \\
\hline & N. gosteliae & & 100 & & 0 & 116 & 0 & 116 \\
\hline & UTU & 100 & & 0 & 0 & 54 & 54 & \\
\hline & total & 99.6 & & 97 & 116 & 55 & 268 & \\
\hline \multirow[t]{4}{*}{ elytron } & N. cordicollis & & 99 & & 97 & 0 & 1 & 98 \\
\hline & N. gosteliae & & 98.3 & & 0 & 114 & 2 & 116 \\
\hline & UTU & 94.4 & & 2 & 1 & 51 & 54 & \\
\hline & total & $\mathbf{9 7 . 8}$ & & 99 & 115 & 54 & 268 & \\
\hline \multirow[t]{4}{*}{ median lobe of aedeagus } & N. cordicollis & & 100 & & 22 & 0 & 0 & 22 \\
\hline & N. gosteliae & & 95.2 & & 0 & 20 & 1 & 21 \\
\hline & UTU & 100 & & 0 & 0 & 17 & 17 & \\
\hline & total & 98.3 & & 22 & 20 & 18 & 60 & \\
\hline
\end{tabular}


were defined as unknown taxonomic unit or UTU. The specimen number in each group is provided in Table 1, as total number. The material studied was loaned from institutions and private collectors (for the full list and the collections' acronyms, see Acknowledgements).

We quantified some of the anatomical traits typically employed for taxonomic identification in Nebriola, namely the pronotum, right elytron, and median lobe of aedeagus (Palestrini et al., 2012). The structures were photographed by a Leica Z16Apo stereoscopic dissecting scope (Leica Microsystems AG, Wetzlar, Germany), ensuring that the specimens were plane-positioned.

Point configurations (Fig. 1) were set by tpsDig 2.17 (Rohlf, 2013a), coding points as landmarks and semilandmarks by tpsUtil 1.55 (Rohlf, 2013b), following the semilandmarks method (Tocco et al., 2011; Palestrini et al., 2012). Goodness of fit for points configuration was tested using tpsSmall 1.25 (Rohlf, 2013c). The pronotum centroid size (CS_pro) was chosen as a measure of overall body size. The CS values were not log-transformed, since data transformation made no difference in the results (Viscosi and Cardini, 2011).

\section{Shape analysis}

The relative warp analysis (RWA) was conducted as implemented in tpsRelw 1.49 (Rohlf, 2010), retaining the aligned configurations (AC), centroid size values (CS), and relative warp scores (RWs) for the following analyses. For each anatomical structure, shape variation scatterplots within samples summarised by relative warps 1 and 2 were drawn by SPSS Statistics v19 (IBM SPSS ${ }^{(\mathcal{O})}$. The same software was also employed for subsequent statistical analyses, unless otherwise stated. A classification matrix (canonical variate analysis - CVA). derived from trait shape variation was obtained employing all the RWs which explained together the $100 \%$ of the overall shape variation (Tocco et al., 2011; Palestrini et al., 2012). AC scores of each structure were employed to analyse specimen group membership through MANOVA (multivariate analysis of variance), as implemented in tpsRegr v1.38 (Rohlf, 2011). Shape covariation between traits using partial least square (PLS) analysis of anatomical structures (AC values) in pairs was tested employing tpsPLS v1.19 (Rohlf, 2013d).

\section{Size analysis}

The data distribution among groups for each structure was examined by comparing taxa median values using a non-parametric Kruskall-Wallis test (KWT), and subsequently the differences among datasets were verified. Regression analysis (relative size analysis - RSA) was applied to test relative size (Jungers et al., 1995) among individuals for each proposed group. The full and reduced ANCOVAs were employed in succession to test the size differences among the groups for each structure removing the body size effect. The geometric relationships between the Maximum Pronotal Width (MPW, see Palestrini et al., 2012), and the CS values of the structures in the three groups were examined using reduced major axis (RMA) regression. The size heterogeneity in the taxa was analysed as implemented in SMATR v2.0 (Falster et al., 2006), using the test for common slopes among groups with the default parameters.

\section{Size and shape analysis}

Differences in the covariation between size (CS values) and shape (AC values) for trait pairs within and among the three groups were evaluated using MANCOVA (multivariate analysis of covariance) (Minton et al., 2011; Zelditch et al., 2012) as implemented in tpsRegr v1.38 (Rohlf, 2011).

\section{Linear measurements}

The following measurements were recorded for the species description: 1) the overall length from the tip of the mandibles to the end of the elytra $(=\mathrm{L}) ; 2)$ the ratio of pronotum width/pronotum length (= PW/PL); and 3) the ratio of elytra width/elytra length (= EW/EL).

\section{Results}

A very good fit between shape and tangent space was identified using tpsSmall for all anatomical traits, i.e. slope $=0.99$, and correlation (uncentered) $=1.0$. These results indicated that the samples geometric heterogeneity was small enough to allow the subsequent analyses.

\section{Shape analysis}

Twenty-eight RWs were obtained from the pronotum RWA, 20 RWs for the right elytron, and 22 RWs scores were retrieved for the median lobe of aedeagus. In addition, more that $85 \%$ of the overall shape variation was explained by the first four (right elytron and median lobe of aedeagus), and first five RWs (pronotum). 

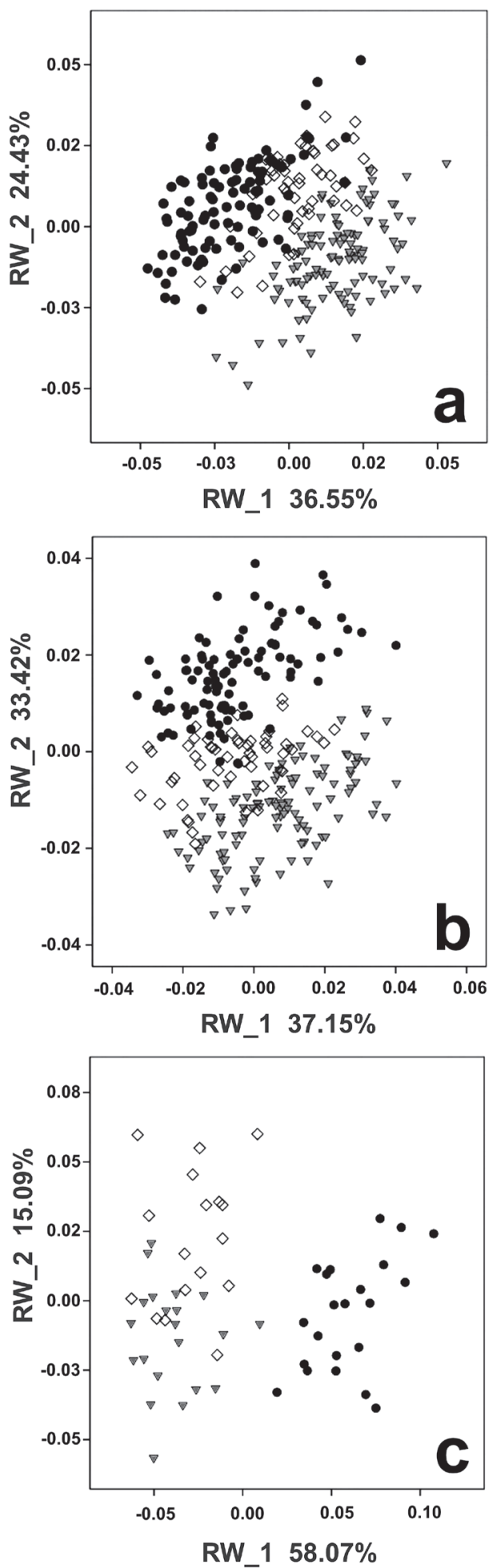

Fig. 2. Shape analysis (relative warp): a) scatterplot of pronotum, b) right elytron and c) median lobe of aedeagus. Black dots = Nebria cordicollis, grey triangles $=N$. gosteliae, white rhombs $=$ UTU.
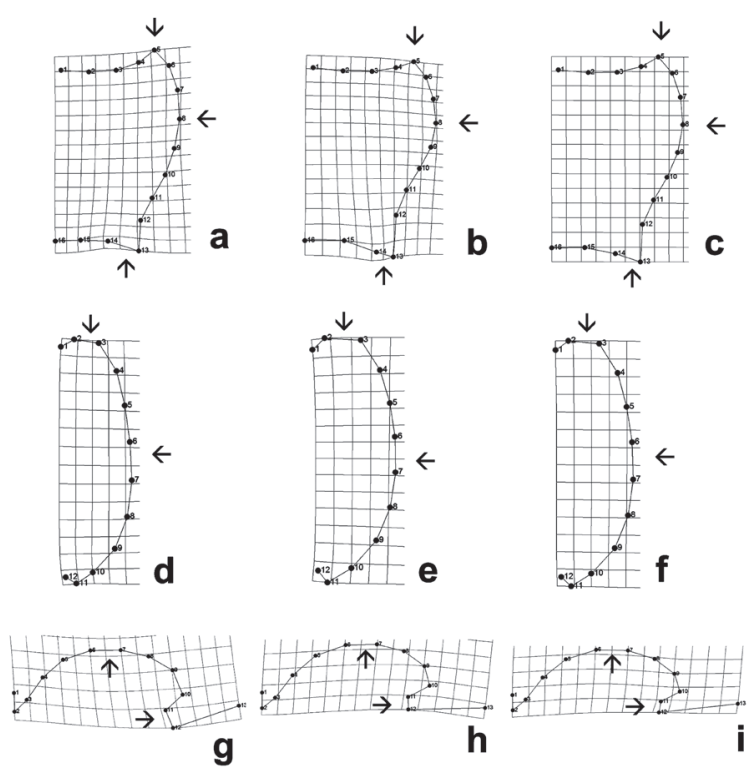

Fig. 3. Deformation grids: a) pronotum of Nebria cordicollis, b) $N$. gosteliae and c) UTU; d) right elytron of $N$. cordicollis, e) $N$. gosteliae and f) UTU; g) median lobe of aedeagus of N. cordicollis , h) N. gosteliae and i) UTU.

For each structure (right elytron, median lobe of aedeagus, and pronotum), the first two RWs were plotted to provide the relative position of individuals, and data were grouped to visualise shape differences among groups (Fig. 2). The shape variation highlighted for each group was compared with the consensus through the visualization of the grid deformations for each anatomical trait (Fig. 3).

For the pronotum, in the first two RWs scatterplot (Fig. 2a), groups were differentiated, although partly superimposed. Nebria cordicollis (Fig. 3a-c) showed a more concave fore margin, and a more elongate fore angle than $N$. gosteliae and UTU. The hind angle was shorter in the former taxon, and turned outward; in $N$. gosteliae the hind angle was rectilinear and elongate back towards the right elytron. In the same taxon, the lateral curvature was more rounded than in $N$. cordicollis and UTU, which shared a similar pronotum curvature. The hind angle in UTU was rectilinear, but less elongate than in N. gosteliae. It is noteworthy that as a rule, UTU was placed in an intermediate position between $N$. cordicollis and $N$. gosteliae in all RW pair scatterplots examined.

The first two RWs scatterplot for the right elytron (Fig. 2b) showed a partial superimposition among the two taxa and the UTU. The overall shape variation of 
the right elytron was far less marked for the three groups (Fig. 3d-f), which were characterised by increased uniformity in shape for the right elytron, i.e. decreased variability than previously observed for the pronotum, but the groups were nevertheless distinct. Consistent with the pronotum plots, in the elytron plots the UTU group was typically placed between the $N$. cordicollis and N. gosteliae groups, with variable overlap in the different combinations of RW pairs. Overall, $N$. cordicollis right elytron was the narrowest, that of $N$. gosteliae was the broadest, and the two species exhibited no overlap in the scatterplot (Fig. 2b). Differences in the right elytron among groups were primarily related to width of the proximal margin, and the distal third, which was more or less enlarged.

The first two RWs scatterplot for median lobe of aedeagus (Fig. 2c) clearly differentiated the three groups. Shape variation showed increased diversity in $N$. cordicollis, $N$. gosteliae, and UTU for median lobe of aedeagus compared with the other anatomical structures examined. The median lobe of aedeagus (Fig. 3g-i) showed distinct differences among groups, with the curvature of the entire structure far more accentuated in $N$. cordicollis than in $N$. gosteliae and UTU, and the basal portion was clearly different among the three groups.

The CVA statistically confirmed the proposed groups. Following a standard semilandmarks approach (Palestrini et al., 2012), we employed for the analysis only the RWs which together explained the $100 \%$ of the overall shape variation, i.e. 23 of $28 \mathrm{RWs}$ for the pronotum, 15 of $20 \mathrm{RWs}$ for the elytron, and 18 of 22 RWs for the median lobe of aedeagus. CVA revealed significant results (Table 1) for each anatomical trait.

Significant results were detected for the pronotum, the right elytron, and median lobe of aedeagus using Wilks' Lambda and Goodall F-test (Table 2). Permutation tests confirmed correct membership of individuals to the proposed groups, i.e. N. cordicollis, $N$. gosteliae, and UTU as three distinct groups, the percent of Goodall $\mathrm{F}$ values $\geq$ observed being always equal to $0.01 \%$ (Table 2). The shape variation among groups exhibited significant results for each structure, and the pronotum showed the highest significance level of membership among groups.

PLS analysis of shape covariation for the pronotum and right elytron showed a high covariance percentage value for the first (D1) of 20 dimensions obtained through the cross set analysis (Table 3), while the remaining dimensions exhibited values lower than 5\%. In addition, the correlation coefficient $r$-value between shapes was high for D1 (Fig. 4), and higher than expected by chance alone. These results confirmed that the hypothesised relationship between pronotum and elytron shape variation was significant within and among groups, therefore the covariation pronotum and elytron shape pattern showed characteristic differences among the proposed groups. Similar significant results were observed for pronotum/median lobe of aedeagus, and right elytron/median lobe of aedeagus pairs (Table 3), supporting shape variation differences within each group for the three anatomical traits, with each group maintaining a distinct position on the plots (Fig. 4).

\section{Size analysis}

The KWT pairwise comparisons (Table 4) indicated groups' significant size differences for pronotum, right elytron and median lobe of aedeagus, in that the distributions of CS values were not the same across the proposed groups. Besides, the pairs N. cordicollis - UTU (for the right elytron) and N. gosteliae - UTU (for the median lobe of aedeagus) displayed a lower significant difference in size than the other pairs (Table 4).

The scatterplots (Fig. 5) showed a relatively high correlation between the pronotum and the elytron in the three groups, while evidence for a very low correlation between the pronotum and median lobe of aedeagus was detected. Results confirmed that a linear model was adequate to predict the outcome variable (the interaction values are shown in Table 5). For right elytron, the full ANCOVA (results not shown), and the following reduced ANCOVA (Pairwise Comparisons, Table 6) verified that the three groups were significantly different for elytron size, once body size effect was removed. The full ANCOVA (results not shown) and reduced ANCOVA for CS_mla revealed significant differences among groups, following the removal of body size effect (Pairwise Comparisons, Table 6).

The RMA analysis among groups indicated that slopes were significantly $(\mathrm{p}<0.05)$ heterogeneous for the pronotum and the right elytron. The subsequent post-hoc multiple comparisons analysis of slopes among groups for the pronotum emphasised that all three groups exhibited significant slope differences, with UTU showing increased divergence. The slope comparisons for the right elytron gave analogous significant differences in slopes for the three groups. The RMA analysis for median lobe of aedeagus did not detect significant differences $(p>0.05)$; therefore a common slope was assessed for the three groups. In 

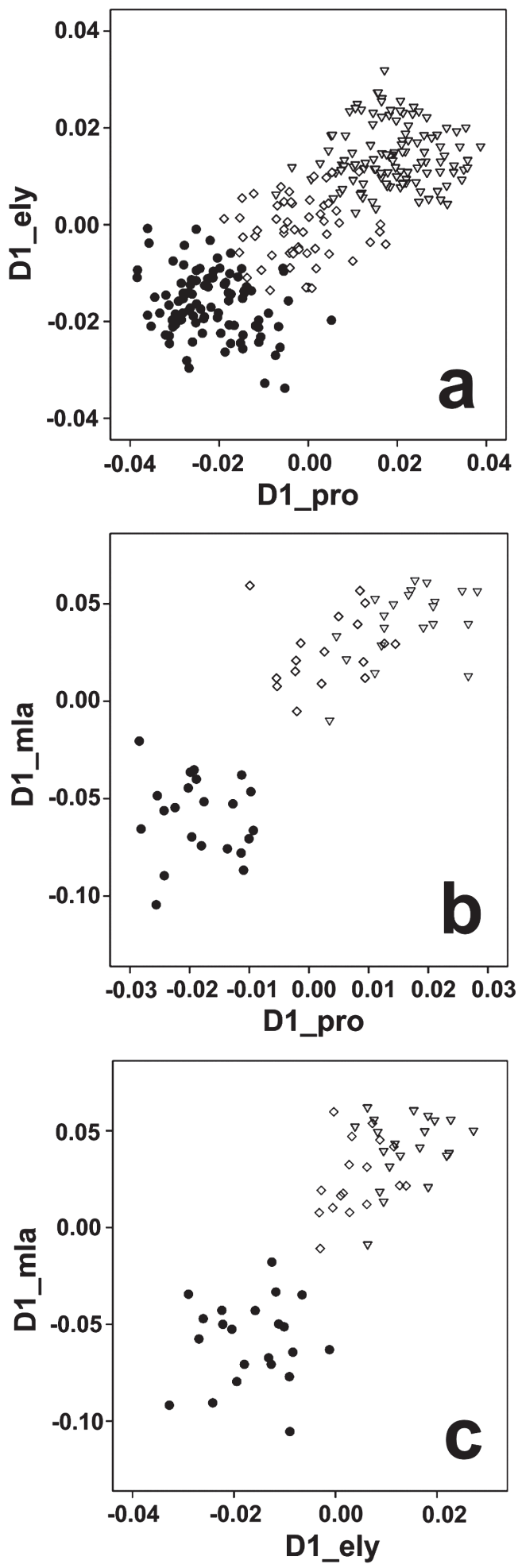

Fig. 4. Plots of partial least square analysis of: a) pronotumright elytron, b) pronotum- median lobe of aedeagus and c) right elytron-median lobe of aedeagus. Black dots $=N$. cordicollis, grey triangles $=N$. gosteliae, white rhombs $=$ UTU.
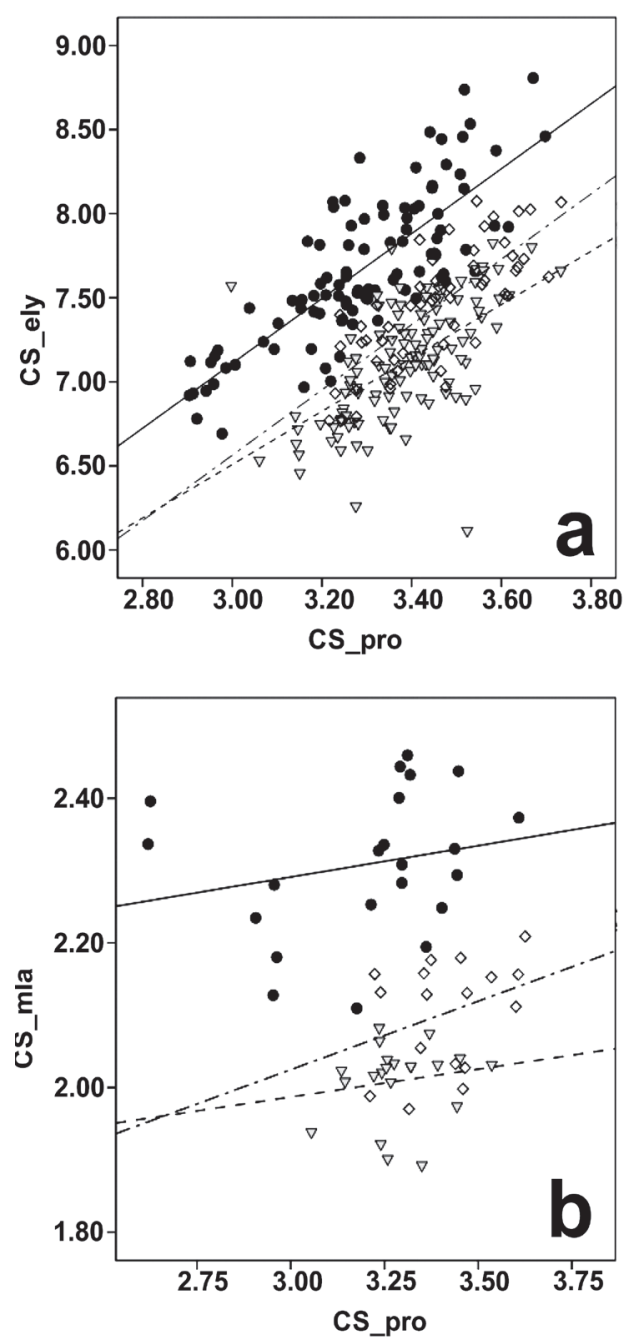

Fig. 5. Plot of the centroid size values of elytron (CS_ely) and median lobe of aedeagus (CS_mla) onto the centroid size values of pronotum (CS_pro, independent variable in the Regression analysis). Black dots $=$ Nebria cordicollis, grey triangles $=N$. gosteliae, white rhombs $=$ UTU. 
Table 2. Results of the multivariate tests of significance in MANOVA for pronotum, right elytron and median lobe of aedeagus, including goodness of fit value and the validation of the proposed membership to the groups. * percent of Goodall $\mathrm{F}$ values $\geq$ observed

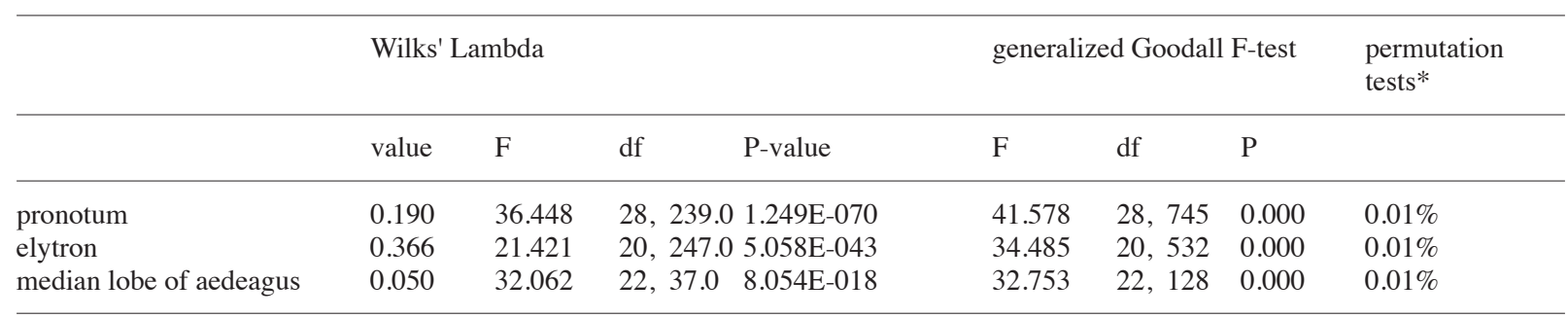

Table 3. Results of the partial least square analysis of shapes covariation of the anatomical traits in pairs (i.e, pronotum/right elytron, pronotum/median lobe of aedeagus, right elytron/median lobe of aedeagus).

\begin{tabular}{llll}
\hline & $\begin{array}{l}\text { cross set analysis } \\
\text { percent covariance }\end{array}$ & r & $\begin{array}{l}\text { permutation tests } \\
\text { percent of correlations } \geq \text { observed }\end{array}$ \\
\hline pronotum vs. elytron & $95.08 \%$ & 0.805 & $0.01 \%$ \\
pronotum vs. median lobe of aedeagus & $85.34 \%$ & 0.847 & $0.01 \%$ \\
elytron vs. median lobe of aedeagus & $95.73 \%$ & 0.838 & $0.01 \%$ \\
\hline
\end{tabular}

Table 4. Results of the non-parametric independent-samples Kruskall-Wallis test, $* * * P<0.001, * P<0.05$.

\begin{tabular}{|c|c|c|c|c|}
\hline & pairwise Comparison & mean ranks difference & std. error & sig. \\
\hline \multirow[t]{3}{*}{ pronotum } & N. cordicollis - N. gosteliae & -39.423 & 10.635 & $* * *$ \\
\hline & N. cordicollis - UTU & -72.762 & 13.136 & $* * *$ \\
\hline & N. gosteliae - UTU & -33.339 & 12.769 & $* * *$ \\
\hline \multirow[t]{3}{*}{ elytron } & N. cordicollis - N. gosteliae & -91.623 & 10.635 & $* * *$ \\
\hline & N. cordicollis - UTU & -31.114 & 13.136 & $*$ \\
\hline & N. gosteliae - UTU & -60.513 & 12.769 & $* * *$ \\
\hline \multirow[t]{3}{*}{ median lobe of aedeagus } & $N$. cordicollis - N. gosteliae & -34.169 & 5.328 & $* * *$ \\
\hline & N. cordicollis - UTU & -21.160 & 5.624 & $* * *$ \\
\hline & N. gosteliae - UTU & -13.008 & 5.698 & $*$ \\
\hline
\end{tabular}

Table 5. Relative size analysis, regression of CS_pro vs. CS_ely, and vs. CS_mla, *** $P<0.001$.

\begin{tabular}{|c|c|c|c|c|c|c|c|c|c|}
\hline & & $\mathrm{R}$ & $\mathrm{R} 2$ & df & $\mathrm{F}$ & a & $\mathrm{b}$ & sig. & \\
\hline \multirow[t]{3}{*}{ elytron } & N. cordicollis & 0.798 & 0.636 & 1,96 & 167.820 & 1.929 & 1.322 & 0.000 & $* * *$ \\
\hline & N. gosteliae & 0.592 & 0.351 & 1,11 & 61.618 & 1.586 & 1.751 & 0.000 & $* * *$ \\
\hline & UTU & 0.760 & 0.577 & 1,52 & 71.030 & 1.943 & 0.735 & 0.000 & $* * *$ \\
\hline \multirow{3}{*}{$\begin{array}{l}\text { median lobe of } \\
\text { aedeagus }\end{array}$} & N. cordicollis & 0.224 & 0.050 & 1,20 & 1.052 & 0.087 & 2.031 & 0.317 & ns \\
\hline & N. gosteliae & 0.162 & 0.026 & 1,19 & 0.513 & 0.077 & 1.756 & 0.483 & ns \\
\hline & UTU & 0.328 & 0.107 & 1,15 & 1.803 & 0.189 & 1.457 & 0.199 & $\mathrm{~ns}$ \\
\hline
\end{tabular}

Table 6. Reduced ANCOVA's pairwise comparisons table, with the Bonferroni adjustment for multiple comparisons, $* * * P<0.001, * *$ $P<0.01$.

\begin{tabular}{llll}
\hline dependent variable & species pair & mean difference & sig. \\
\hline CS_ely & N. cordicollis - N.gosteliae & 0.724 & $* * *$ \\
& N.cordicollis - UTU & 0.523 & $* * *$ \\
CS_mla & UTU - N.gosteliae & 0.201 & $* * *$ \\
& N.cordicollis - N.gosteliae & 0.308 & $* * *$ \\
& N.cordicollis - UTU & 0.226 & $* *$ \\
& UTU - N.gosteliae & 0.082 & $* *$ \\
\hline
\end{tabular}


addition, a line comparison showed a non-shift along the common slope.

\section{Size and shape analysis}

MANCOVA (Rohlf, 2011; Zelditch et al., 2012) confirmed that a common slope was sufficient for the pronotum data, and pronotum size (CS_pro, the main factor) was statistically significant (Wilks' Lambda $\mathrm{Fs}=17.11, \mathrm{df}=112,935.9, \mathrm{P}<0.001)$. MANCOVA results showed that separate slopes were required to evaluate right elytron shape and size covariation among groups; therefore further analyses could not be conducted. Furthermore, MANCOVA established that size and shape did not exhibit similar covariation among groups in the elytron dataset. Similar to the pronotum results, MANCOVA results indicated that a common slope for median lobe of aedeagus was sufficient, and size (here, CS_mla) was statistically significant (Wilks' Lambda Fs $=3.54$, df $=88,133.0$, P $<0.001)$.

\section{Discussion}

The results of this study showed that the three syntopic taxa from the Pennine-Lepontine Alps were distinct, therefore the UTU was defined as an independent taxonomic entity, and described as Nebria (Nebriola) casalei sp. nov. (see Appendix). The new species was determined through the GM approaches, which confirmed once again the power of the method as a tool to discriminate among taxa. Our present findings fully corroborated previous observations by various researchers, and particularly a report by Vigna Taglianti et al. (1998), who first examined material collected by A. Casale in the Lepontines Alps (Zeda Mt.) suggesting some specimens as a probable new species (A. Casale, pers. comm.).

The GM methods quantitatively delimited the morphological characteristics that distinguished the new species, $N$. casalei, from $N$. cordicollis and $N$. gosteliae recorded from the Pennine and Western Lepontine Alps area. The three species were clearly distinct in shape and size for the anatomical traits examined (pronotum, right elytron, and median lobe of aedeagus), and the differences can be summarised as follows:

A) Shape Analysis: 1) for each anatomical trait, the three species exhibited differences in shape variation, although some problems were observed due to differences in group sample size (RWA); 2) the three species were significantly different (CVA); 3 ) the pronotum showed the greatest diversity among the three species (MANOVA); 4) the pairs pronotum right elytron, and right elytron - median lobe of aedeagus covaried more significantly than the pronotum - median lobe of aedeagus pair. In addition, three distinct groups were plotted based on covariance, and $N$. gosteliae and N. casalei remained always closer (PLS analysis).

B) Size Analysis: 5) separate analysis of the three anatomical structures revealed significant differences among species, and the pronotum displayed the greatest diversity (KWT); 6) right elytron size was significantly related to body size, but median lobe of aedeagus size was not significantly related to body size (RSA); 7) N. casalei showed increased pronotum size diversity compared to $N$. cordicollis and $N$. gosteliae, while all three taxa were equally different in right elytron size (RMA).

C) Combined Shape and Size Analysis: 8) shape/ size covariation was similar across groups (common slope) for the pronotum and median lobe of aedeagus, however the three groups exhibited different covariation patterns (different slopes) for the right elytron (MANCOVA).

The GM approaches show potential to investigate the hypothesised presence of cryptic species within Nebriola; and might serve to resolve the systematics of subgenus Nebriola. The phylogenetic relationships of subgenus Nebriola have not been thoroughly examined, although some biogeographic hypotheses have been generated based on the species present distributions. Ledoux and Roux (2005) indicated the $\mathrm{Ne}$ briola clade is sister to the Boreonebria-Pseudonebria clade, and populated the Alps and Pyrenees from a Boreonebria ancestor. Pseudonebria exhibited similar geographic isolation in Asia. It is hypothesised that Nebriola diverged from an ancient lineage of taxa related to Boreonebria and Pseudonebria. Species migrated into the Western Palearctic through a variety of dispersal mechanisms, such as to establish at higher altitudes, occasionally use caves, and as environmental temperatures raised, some species exhibited concurrent latitudinal (northwards) and elevational range increases (Ledoux and Roux, 2005).

This proposed isolation might explain two large clades identified in Nebriola (Ledoux and Roux, 2005), where a northeast component comprises species of the $N$. cordicollis species-group with many taxonomic entities whose rank remains unresolved. 
Nebria casalei can be included in the $N$. cordicollis species-group on the basis of external and internal morphological characters (see the diagnosis below for details), however the species is more closely related to $N$. gosteliae than to $N$. cordicollis.

Subgenus Nebriola appears to be a group of taxa well suited to study and understand developmental trends, and the geographic and climatic conditions leading to the origin of species in the Alpine area.

In the Northeastern Alps, refugia created since the last glacial maximum (dating back 21,000 YBP) has shifted, and biodiversity hotspots are evident (Habel and Assmann, 2010). From South European Mountain refugia, cold-adapted species expanded their range due to intrusion by uninhabitable continental ice. In historical biogeography, refugial distribution patterns remain a fundamental question.

Again, Nebriola species are wingless carabids, characterised by low dispersion capacity, which likely confines the species to mountain environments, similar to relictary island habitats. Among other attributes, the species habitat is characterised by damp and cold conditions, which results in its ecological niche. A strict dependence on strongly limiting ecological factors (water, altitude, and temperature) in an alpine environment suggests the three species examined in this study can serve as viable models for climate change. Consequently, these taxa should be considered for long-term alpine biodiversity conservation management and monitoring. In addition, our results provided evidence that Nebriola is a particularly interesting group due to the potential presence of cryptic species, and requirements for taxon-specific conservation strategies within the subgenus.

\section{Acknowledgements}

We would thank the Museum Curators [M. Valle (MBCG - Museo di Scienze Naturali Enrico Caffi, Bergamo, Italy) and R. Poggi (MSNG - Museo Civico di Storia Naturale Giacomo Doria, Genova, Italy)], and the private collectors [L. Bisio (CBi, Torino, Italy), A. Casale (CCa, Torino, Italy), P. M. Giachino (CGi, Torino, Italy), C. Ghittino (CGh, Torino, Italy), R. Monguzzi (CMo, Milano, Italy), R. Pescarolo (CPe, housed at Museo Civico di Storia Naturale, Carmagnola, Torino, Italy), and R. Sciaky (CSc, Milano, Italy)] that provided the Nebriola material on loan. We are very grateful to G. Allegro (CRA-PLF, Casale Monferrato, AL) for the photo of the new species and to A. Casale (University of Sassari) for his critical remarks. We are very grateful to Dr. M. Schilthuizen and to an unknown reviewer for the kind suggestions that contributed to the improvement of the manuscript.

\section{References}

Bänninger M. 1949-50. Die Rassen der Nebria (Nebriola) cordicollis Chd. Und ihre Verbreitung. Entomologische Blätter 45/46: $1-9$.

Bari B. 1971. Il maschio di N.(Nebriola) kochi Schatzm. e la Nebria kochi winkleri n. ssp. delle Alpi Pennine (Coleopera Carabidae). Bollettino della Società Entomologica Italiana 103: 124-132.

Bisio L. 1998. Note sulle popolazioni di alcune Nebria del subg. Nebriola e di Nebria crenatostriata in Piemonte (Coleoptera Carabidae). Rivista Piemomtese di Storia Naturale 19: 151192.

Casale A, Vigna Taglianti A. 1993. I Coleotteri Carabidi delle Alpi occidentali e centro-occidentali (Coleoptera, Carabidae). Biogeographia 18 (1995): 391-427.

Daniel K. 1903. Bestimmungstabellen der europäischen Koleopteren LII. (Nebriini, Notiophilini, Trachypachydini, Epactiini, Elaphrini und Lorocerini. Münchener Koleopterologische Zeitschrift 1: 155-173.

Falster DS, Warton DI, Wright IJ. 2006. SMATR: Standardised major axis tests and routines, ver 2.0. Free software from http://www.bio.mq.edu.au/ecology/SMATR/ (18 June 2013)

Focarile A. 1976. Sulla Coleotterofauna alticola del Monte Barbeston m 2482 (Val Chalamy) e del monte Nery m 3076 (Val d'Ayas). Revue valdôtaine d'Histoire Naturelle 30: 86125.

Focarile A, Casale A. 1978. Primi rilevamenti sulla Coleotterofauna alticola del Vallone di Clavalité (Fenis, Aosta). Revue valdôtaine d'Histoire Naturelle 32: 6-92.

Habel JC, Assmann T. 2010. Relict Species - Phylogeography and Conservation Biology. Berlin: Springer.

Huber C, Molenda R. 2004. Nebria (Nebriola) praegensis sp. nov., ein Periglazialrelikt im Süd Schwarzwald/Deutschland, mit Beschreibung der Larven (Insecta, Coleoptera, Carabidae). Contributions to Natural History 4: 1-28.

Huber C., Szallies A, Baur H, Giachino PM. 2010. Nebria (Nebriola) gosteliae sp. nov. from the Penninian Alps near Biella, Piemonte, Italy (Coleoptera: Carabidae, Nebriinae). Contributions to Natural History 15: 9-27.

Jeannel R. 1941. Faune de France. 39. Coléoptères Carabiques I. Paris: P. Lechevalier.

Jungers WL, Falsetti AB, Wall CE. 1995. Shape, relative size, and size-adjustments in morphometrics. Yearbook of Physical Anthropology 38: 137-161.

Ledoux G, Roux P. 2005. Nebria. Faune mondiale. Lyon: Société linnéenne de Lyon et Muséum de Lyon.

Löbl I, Smetana A. 2003. Catalogue of Palaearctic Coleoptera. Volume 1. Archostemata - Myxophaga - Adephaga. Stenstrup: Apollo Books.

Lorenz W. 2005. Systematic list of extant Ground Beetles of the World (Insecta Coleoptera "Geadephaga": Trachypachidae and Carabidae incl. Paussinae, Cicindelinae, Rhysodinae). Tutzing (published by the author).

Magistretti M. 1965. Coleoptera. Cicindelidae, Carabidae. Catalogo topografico. Fauna d'Italia. Bologna: Calderini.

Minton RL, Lewis EM, Netherland B, Hayes DM. 2011. Large Differences over Small Distances: Plasticity in the Shells of Elimia potosiensis (Gastropoda: Pleuroceridae). International Journal of Biology 3: 23-32. 
Palestrini C, Roggero A, Hernández Nova LK, Giachino PM, Rolando A. 2012. On the evolution of shape and size divergence in Nebria (Nebriola) ground beetles (Coleoptera, Carabidae). Systematics and Biodiversity 10: 147-157.

Rohlf FJ. 2010. tpsRelw v1.49. Free software from http://life. bio.sunysb.edu/morph/morphmet.html/ (18 June 2013)

Rohlf FJ. 2011. tpsRegr v1.38. Free software from http://life. bio.sunysb.edu/morph/morphmet.html/ (18 June 2013)/.

Rohlf FJ. 2013a. tpsDig v2.17. Free software from http://life. bio.sunysb.edu/morph/morphmet.html/ (18 June 2013)

Rohlf FJ. 2013b. tpsUtil v1.55. Free software from http://life. bio.sunysb.edu/morph/morphmet.html/ (18 June 2013)

Rohlf FJ. 2013c. tpsSmall v1.25. Free software from http://life. bio.sunysb.edu/morph/morphmet.html/ (18 June 2013)

Rohlf FJ. 2013d. TpsPLS v1.19. Free software from http://life. bio.sunysb.edu/morph/morphmet.html/ (18 June 2013)

Seifert B. 2009. Cryptic species in ants (Hymenoptera: Formicidae) revisited: we need a change in the alpha-taxonomic approach. Myrmecological News 12: 149-166.

Tocco C, Roggero A, Rolando A, Palestrini C. 2011. Inter-specific shape divergence in Aphodiini dung beetles: the case of Amidorus obscurus and A. immaturus. Organisms Diversity and Evolution 11: 263-273.

Vigna Taglianti A. 2005. Checklist e corotipi delle specie delle specie di Carabidae della fauna italiana. Appendice B, pp.
186-225. In: Brandmayr P, Zetto T, Pizzolotto R, eds. I Coleotteri Carabidi per la valutazione ambientale e la conservazione della biodiversità. Manuale operativo 34. Roma: APAT, Manuali e Linee Guida.

Vigna Taglianti A, Audisio PA, De Felici S. 1998. I Coleotteri Carabidi del Parco Nazionale della Val Grande (Verbania, Piemonte). Rivista Piemontese di Storia Naturale 19: 193245.

Viscosi V, Cardini A. 2011. Leaf Morphology, Taxonomy and Geometric Morphometrics: A Simplified Protocol for Beginners. PLoS ONE 6(10): e25630. doi:10.1371/journal. pone. 0025630

Zelditch ML, Swiderski DL, Sheets HD. 2012. A Practical Companion to Geometric Morphometrics for Biologists: Running analyses in freely-available software. Free download from http://booksite.elsevier.com/9780123869036/ (18 June 2013)

Received: 20 November 2012

Revised and accepted: 20 November 2013

Published online: 20 December 2013

Editor: J.W. Arntzen 


\section{Appendix}

by Pier Mauro Giachino

Nebria (Nebriola) casalei Giachino sp. nov. Figs 6-7

Diagnosis. Nebria (Nebriola) casalei sp. nov. is included in the $N$. cordicollis species-group (sensu Ledoux and Roux, 2005) based on the highlighted external and internal morphological characters, including the elongated and posteriorly dilated right elytron, and the more slender shape of the median lobe of aedeagus. Compared to other species of the N. cordicollis species-group, $N$. casalei sp. nov. differs in the following characters. Nebria casalei is distinguished from N. cordicollis Chaudoir, 1837 by a more transverse pronotum, decreased elytra length with less evident striae punctuation, more elongated labial palpi, increased curvature to the median lobe of aedeagus (compared to $N$. cordicollis), and internal sac of the aedeagus with a tuft of mixed short and long setae (only long setae in N. cordicollis). Nebria casalei is distinguished from N. gosteliae Huber, 2010 by shorter hind angles and reduced curvature on the lateral sides of the pronotum, more regularly curved median lobe of aedeagus, and internal sac of the aedeagus with a tuft of mixed short and long setae (only long setae in N. gosteliae). Nebria casalei is distinguished from $N$. fontinalis K. and J. Daniel, 1890, by its larger size, anal sternum with one paramedial seta in the male, less regularly curved median lobe of aedeagus (Palestrini et al., 2012), and internal sac of the aedeagus with a tuft of mixed short and long setae (only short setae in $N$. fontinalis).

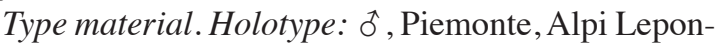
tine, M. Zeda, 2000 m, 19.vi.1977, leg. Casale (MSNG). Paratypes: 1 đo 2 우, Piemonte, Alpi Lepontine, M. Zeda, 2000 m, 19.vi.1977, leg. Casale (CCa); 1 đิ 5 우, M. Zeda (NO), 6.vi.1981, leg. Sciaky (CGi, CSc); 2 ô ô 2 우, Val Vigezzo (VB), Cima d. Laurasca, 2000 m, 6.vii.1997, leg. Monguzzi (CGi, CMo); 1 ô, Alpi Lepontine (VB), Val Vigezzo, Cima d. Laurasca, 2000 m, 6.vii.1997, leg. Monguzzi (CMo); 3 đิ đิ 1 ㅇ, Prealpi Lepontine, Cima d. Laurasca NO, 2000 m, 29.vii.1980, leg. Monguzzi (CGi, CMo); 4 ot ot 2 우 오, Prealpi Lepontine, Cima d. Laurasca, 2000/2200 m, NO, 29.vii.1980, leg. Monguzzi (CGi, CMo); 3 ô ô 2 우 , Prealpi Lepontine, Cima d. Laurasca NO, 2000 m, 26.vii.1980, leg. Monguzzi (CGi, CMo); 2 호 2 우, Val Vigezzo (VB), M. To- gano m 2000, 4.viii.1997, leg. Monguzzi (CGi, CMo);

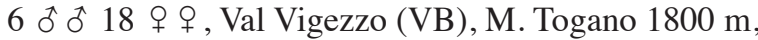
4.viii.1997, leg. Monguzzi (CGi, CMo); 8 ô đิ 10 ㅇ , V. Antoliva, Mte Togano, 2/3.vii.1983, leg. Pescarolo (CPe, CGi); 1 t 1 \& , Piemonte, Val Vigezzo, Cima Laurasca, Cascata a $1700 \mathrm{~m}$ sotto l'Alpe Scaredi, 24.vi.2011, leg. Ghittino (CGh); 24 ô ô 23 우 Piemonte, Druogno (VB), M. Togano, Valle Antolivo, 1700 m, 22.vii.2012, leg. Ghittino (CCa, CGh, CGi). The material is preserved in the collections listed within brackets.

Type locality. Italy, Piedmont, Lepontine Alps, Zeda Mt., $2000 \mathrm{~m}$.

Etymology. I dedicate this new species to my friend Achille Casale who first collected this interesting Nebriola 35 years ago and, generously, allowed me to describe it.

Description. Length $=8.58-9.41 \mathrm{~mm}$ ôे ô, 9.12 $9.91 \mathrm{~mm}$ 우 . Body black, head with two elongated reddish-brown spots of variable markedness. Tips of the mandibles and palpi brownish; antennae with first antennomere always darkened, and antennomeres 2-11 light brownish; legs with black femora, tibiae and tarsi lightened brown.

Head robust, with one supraorbital seta placed near the posterior edge of the eyes; labrum with anterior margin faintly bisinuate, bearing a row of 6 setae; apical margin of clypeus straight. Vertex impunctate, but faintly transversally wrinkled. Maxillary stipes with 8 robust setae basolaterally. Labial palpi long, with penultimate palpomere trisetose. Mentum with a bifid medial tooth. Submentum with a row of 16 setae. Microsculpture of the head isodiametric. Antennae long and slender, extending to the middle of the elytra. Antennal scape subcylindrical, medially faintly thickened, basally narrowed, as long as the eye's diameter, with one dorsal seta.

Pronotum cordate (Fig. 6), transverse (ratio PW/PL $=1.36-1.42$ of $\delta, 1.43-1.45$ o o ), widest at the base of the apical fourth, narrowed basally. Lateral margin regularly rounded anteriorly, strongly sinuated at the basal third, parallel just prior to the basal angles. Anterior angles rounded, protruding; basal angles very acute, and strongly protruding backwards. Lateral groove narrow; apical and basal margination absent. Pronotal disc impunctate, convex with deep basal fovea; anterior and posterior transverse impressions and median longitudinal impression distinct. Basal fovea, anterior and posterior impressions punctate, with the 


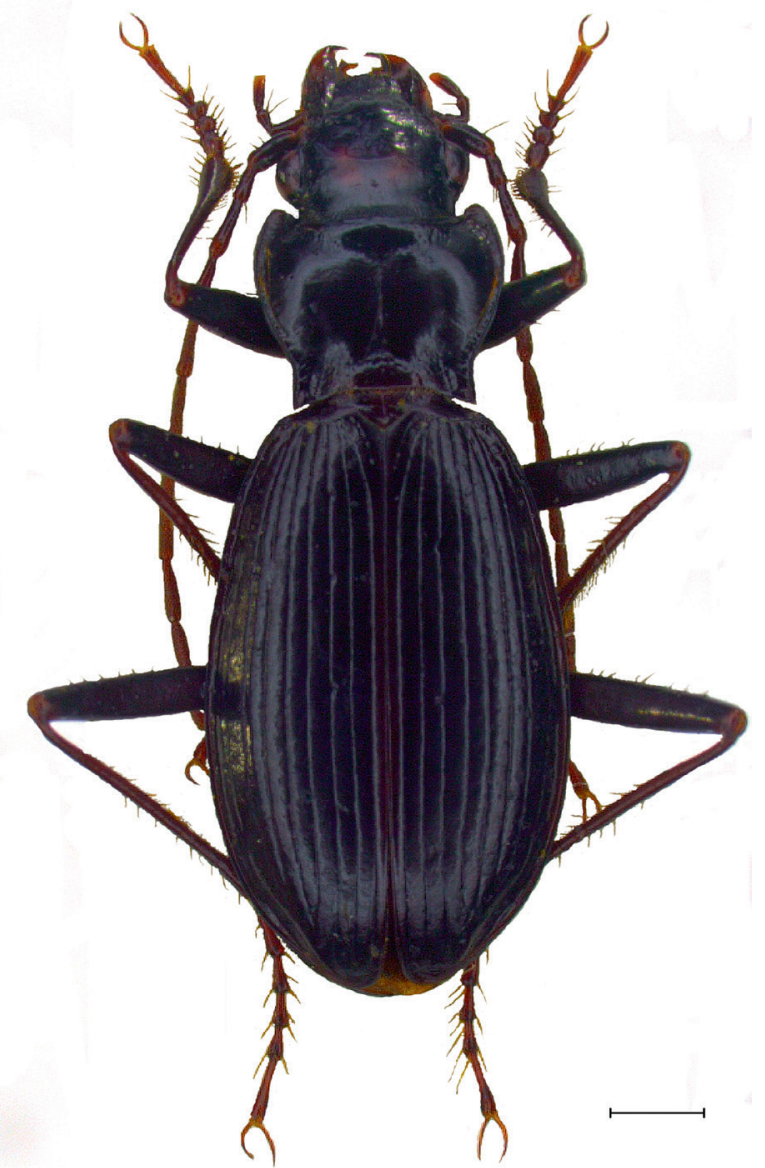

Fig. 6. Nebria (Nebriola) casalei sp. nov. - Habitus of holotype ô. Scale bar: $1 \mathrm{~mm}$.

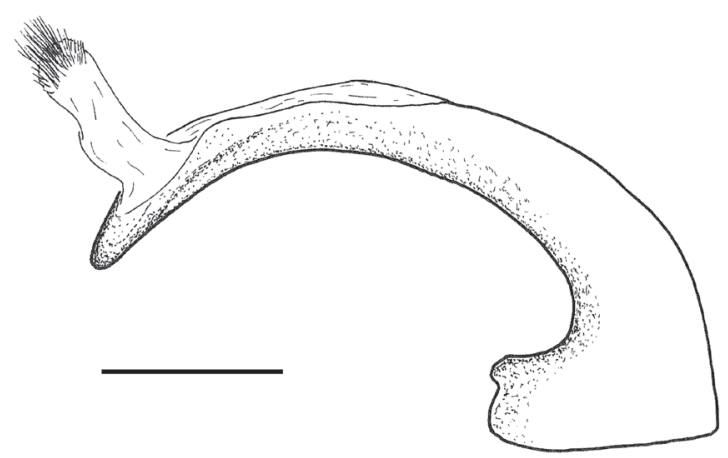

Fig. 7. Nebria (Nebriola) casalei sp. nov. - Median lobe of aedeagus in lateral view, holotype $\widehat{0}$. Scale bar: $0.5 \mathrm{~mm}$.

anterior impression sometimes longitudinally wrinkled; longitudinal impression faintly transversally wrinkled; microsculpture isodiametric. Chaetotaxy: basolateral seta present, 2-4 midlateral setae present at the anterior part of the pronotum. Proepisterna smooth.

Elytra flattened (Fig. 6), coarctated, ovoid-elongate (ratio EW/EL = 0.59-0.63 of o, 0.54-0.61 o o ), with sides evenly rounded, widest after the middle. Humeri reduced, with a marked humeral tooth and a humeral carina; basal margination towards the humeral tooth, straight or slightly sinuate. Striae distinct, weakly punctate, reaching the apex, with intervals weakly convex; apical carena developed. Interval $3^{\text {rd }}$ with 5-7 pores near the $3^{\text {rd }}$ stria. Marginal gutter narrow, interval

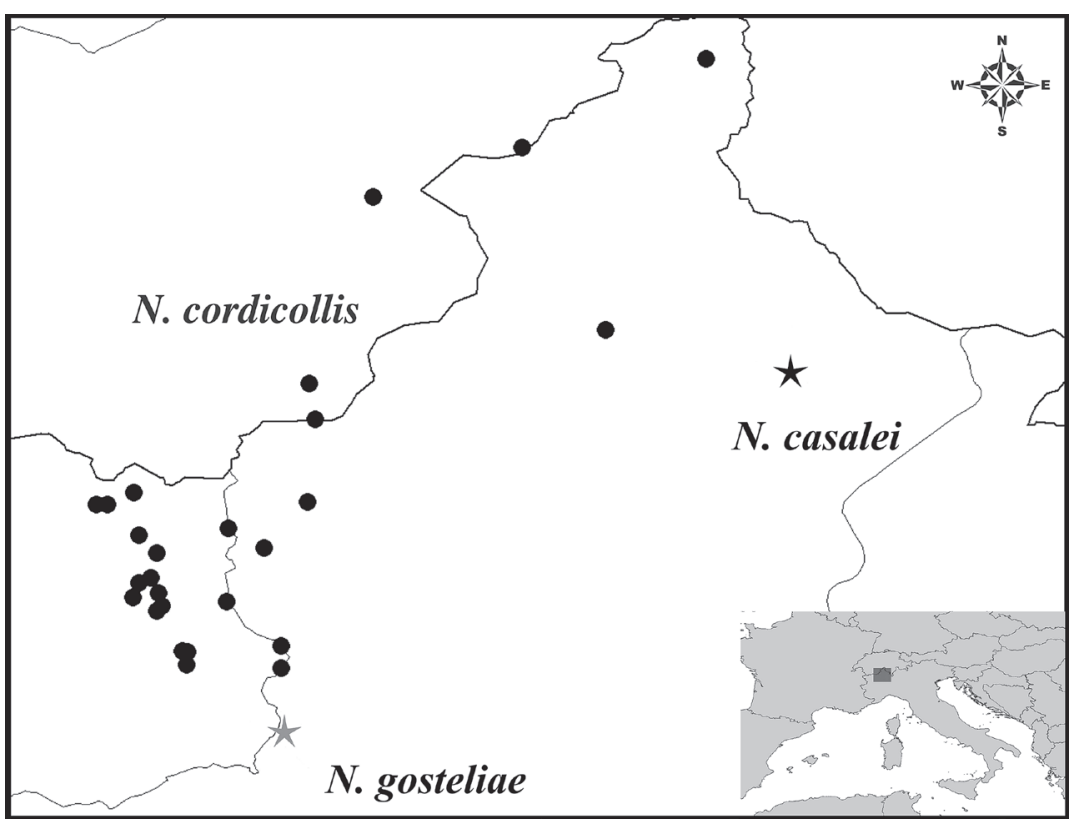

Fig. 8. Distribution of $N$. cordicollis (black dots), N. gosteliae (grey star) and $N$. casalei sp. nov. (black star) in the Pennine and Western Lepontine Alps (Northern Piedmont and Aosta valley). 
$9^{\text {th }}$ with a row of 13 setiferous pores; scutellar pore absent. Elytral disc with isodiametric microsculpture. Meso- and metepisterna faintly punctate; metacoxa with one basal and one apical setae. Metathoracic wings brachypterous.

Ventrites, each with 2-4 posterior paramedial setae. Anal sternum with 1 paramedial seta in the male and 2 in the female. All sterna with faint impressions laterally.

Legs slender. Three basal protarsomeres dilated in the male; metatarsi conspicuously delicate with $5^{\text {th }}$ metarsomere distinctly longer than tarsomeres 3-4.

Aedeagus (Fig. 7) with median lobe slender, regularly curved from apex to base, enlarged at basal orifice; apex slightly turned on the right side. Everted internal sac dorsally with a distinct tuft of mixed shortlong setae in the first third of the shaft.

Geographical distribution. The geographical range (Fig. 8) of N. casalei sp. nov. is restricted to the area of Zeda, Laurasca and Togano Mts., bordered in the south by the Vigezzo Valley and in the northwest by Lake Maggiore (into the Val Grande National Park).

Remarks. Nebria casalei sp. nov. is a hydrophilic, ripicole, cold-stenothermic species, which appears to be more common in summer than in spring (C. Ghittino, pers. comm). Specimens were collected from under stones or near small waterfalls in streamlets at alpine elevations (1800 - $2000 \mathrm{~m})$ in the Laurasca and Togano Mts. (R. Monguzzi and C. Ghittino, pers. comm.), and near a melting snowfield at Zeda Mt. (A. Casale, pers. comm.). In the same habitats, other interesting Coleoptera species were collected, including the Carabidae Nebria (Oreonebria) picea (Dejean, 1826), Bembidion (Testediolum) rhaeticum Heer, 1857, Pterostichus rutilans (Dejean, 1828), and Platynus cfr. de- pressus at Laurasca Mt.; Trechus ceresai Binaghi, 1938 both at Laurasca Mt. and Zeda Mt.; and Dichotrachelus lepontinus Osella, 1971 (Curcolionidae) at Zeda Mt.

All Nebriola are stenoecious, high-altitude, stenothermal (microthermal) species, characterised by similar but distinct ecological habits. Following Focarile (1976), N. cordicollis is regarded a member of the $\mathrm{Ne}$ brietum nivale community that in Piedmont includes sublapidicolous species dwelling in the alpine and higher alpine environments from 2100 to $3000 \mathrm{~m}$ a.s.l., and may be found near snow patches and in scree (Bisio, 1998). N. laticollis, $N$. fontinalis, and N. gosteliae belong to the Nebrietum fontinale community. Nebria laticollis is distributed in cold spring waters (between $+1^{\circ}$ and $+7.2^{\circ} \mathrm{C}$ ) from 1460 to $2700 \mathrm{~m}$ a.s.l. (Focarile and Casale, 1978). Nebria fontinalis exhibits ecological habits similar to $N$. laticollis, and occurs in cold spring and streamlet waters at an altitudinal range between 1500 and $2500 \mathrm{~m}$ a.s.l. (Ledoux and Roux, 2005). Nebria gosteliae is a stenoendemic, hydrophilic, ripicole, and cold-stenothermic species found under stones in streamlets at alpine elevations (1900 2300 m a.s.1.).

Species belonging to the genus Nebria are extremely difficult to sample, given the habitat conditions, and short phenology. Magistretti (1965) already indicated the presence of very few collecting sites for N. cordicollis. Although the chorology of the species was thoroughly investigated during the last thirty years of the $20^{\text {th }}$ century (Bari, 1971; Focarile, 1976; Focarile and Casale, 1978; Bisio, 1998; Huber and Molenda, 2004, Huber et al., 2010), our present understanding of these species should be considered relatively unsatisfactory. 